\title{
Conversão, ordenação, rebentação
}

\author{
Conversion, ordination, breakers
}

Julio Groppa Aquino ${ }^{1}$

\begin{abstract}
Resumo
O presente texto almeja oferecer uma breve reflexão acerca do roteiro cênico do espetáculo Pulsão. Elegendo Caio Fernando Abreu e Michel Foucault como interlocutores, propõe um percurso narrativo lastreado em três movimentos argumentativos assimétricos, porém complementares. Visa-se, desse modo, explorar a hipótese de que a tarefa inexorável das práticas teatrais é a de franquear abrigo e vazão para a potência da vida, esta que, mesmo no duelo-limite com a morte, pode constituir-se como fonte de insuspeitas resistência e criação.
\end{abstract}

Palavras-chave: Narrativa, Performance, Roteiro, Teatro,

\begin{abstract}
This paper aims to offer a brief reflection on the scenic route of the spectacle Pulsão. Electing Caio Fernando Abreu and Michel Foucault as interlocutors, it proposes a narrative journey backed by three asymmetric but complementary argumentative moves. The aim is thus to explore the hypothesis that the inexorable task of theatrical practices is franking shelter and flow to the power of life, which even in the limit duel with death can constitute itself as a source of unsuspected strength and creation.
\end{abstract}

Keywords: Narrative, Performance, Script, Theatre.

\section{Conversão}

[...] agora que a saia-justa-de-couro-cru-sem-fenda-em-nesga pintou, é hora de fazer tudo que sempre quis. E é maravilhoso ver que Tudo Que Sempre Quis é simples, belo, acessível, fácil, do bem. E precioso, exatamente porque pode ser fugaz. Comecei a aprender isso no hospital, continuo aprendendo. (ABREU, 2002, p.319)

Em uma carta à cantora Cida Moreira datada de 18 de novembro de 1994, Caio Fernando Abreu assim sumariza o árduo e, ao mesmo tempo, indelével aprendizado decorrente da experiência de quase um mês de internação ocorrida em agosto daquele mesmo ano, quando o escritor fora levado às pressas para o hospital após uma crise desencadeada pela confirmação de sua contaminação pelo vírus HIV, o qual viria a dizimá-lo menos de dois anos mais tarde.

1 Faculdade de Educação da Universidade de São Paulo (FEUSP-USP) 
Não era a primeira vez que o escritor, dramaturgo e cronista de $O$ Estado de S.Paulo manifestava-se a respeito do tema. Numa série de três cartas publicadas pelo referido jornal intituladas, respectivamente, Primeira, Segunda e Última Carta Para Além Dos Muros, datadas de 21 de agosto, 04 e 18 de setembro de 1994, Caio F. veio a público relatar - só na última delas de modo explícito, ressalve-se - os acontecimentos que tomaram lugar a partir de sua internação. Nos dois primeiros textos, prefere um tom metafórico, indireto.

Uma das passagens da Primeira Carta é exemplar nesse aspecto:

[...] havia a maca de metal com ganchos que se fechavam feito garras em torno do corpo da pessoa, e meus dois pulsos amarrados com força nesses ganchos metálicos. Eu tinha os pés nus na madrugada fria, eu gritava por meias, pelo amor de Deus, por tudo o que é mais sagrado, eu queria um par de meias para cobrir meus pés. Embora amarrado como um bicho na maca de metal, eu queria proteger meus pés. Houve depois a máquina redonda feita uma nave espacial onde enfiaram meu cérebro para ver tudo que se passava dentro dele. E viram, mas não me disseram nada. [...] Tenho medo é desses outros que querem abrir minhas veias. Talvez não sejam maus, talvez eu apenas não tenha compreendido ainda a maneira como eles são, a maneira como tudo é ou tornou-se, inclusive eu mesmo, depois da imensa Turvação. (ABREU, 1996, p.97)

Na Segunda Carta, Caio F. traz à baila os anjos que diz ter encontrado no caminho de seu inferno particular: os do período da manhã com seus uniformes, máscaras e luvas, que mediavam, alimentavam, limpavam, desinfetavam; os da tarde, com seus jeans, cabelos descoloridos, presentes e notícias do mundo exterior. Havia ainda as visitas noturnas de seres incorpóreos que the chegavam pelas antenas, fones e fios; seres já desaparecidos ou, como queria Caio F., "chegados desse Outro Lado de Todas as Coisas" (ABREU, 1996, p.100). Dentre eles, Derek Jarman, Freddy Mercury, Hervé Guibert, Reinaldo Arenas, Cazuza. E deduz:

Aquilo que eu supunha fosse o caminho do inferno está juncado de anjos. Aquilo que suja treva parecia guarda seu fio de luz. Nesse fio estreito, esticado feito corda bamba, nos equilibramos todos. [...] Lá embaixo, uma rede de asas ampara nossa queda. (ABREU, 1996, p.100-101)

Duas semanas mais tarde, já em Porto Alegre, para onde se transferira após a internação em São Paulo, Caio F. enfim elucida aos leitores aquilo que havia anunciado nas semanas anteriores. Admitindo não sentir culpa, nem vergonha ou medo, declara sua disposição de revelar a verdade. Queria narrar ao mundo não apenas o que se the havia passado, mas, principalmente, o que havia angariado da experiência da internação. Para tanto, vale-se da analogia das borboletas que duram apenas um dia fora do casulo. 
Pois há um casulo rompendo-se lento, casca seca abandonada. Após, o voo do Ícaro perseguindo Apolo. E a queda? Aceito todo dia. Conto para você, porque não sei ser senão pessoal, impudico, e sendo assim preciso te dizer: mudei, embora continue o mesmo. (ABREU, 1996, p.103)

Uma espécie de transmutação interior é aquilo que Caio F. subtrai do vivido, consubstanciada na descoberta de uma exuberância serena incrustada no cotidiano: o jardim da casa onde passou a viver, o contato com os parentes e amigos, o que andava a ler, ver e ouvir. Mediante tal conjunto de pequenos e grandes acontecimentos, conclui: "[...] e agradeço, agradeço, agradeço. A vida grita. E a luta, continua"' (ABREU, 1996, p.104)

Como se pode observar no decurso das três cartas, o tom narrativo varia sobremaneira. De uma espécie de expropriação forçosa do próprio corpo - os pés nus na noite fria; as veias abertas; o saber que lhe fora recusado - a uma reapropriação positivadora da experiência da internação - o apego às coisas simples, preciosas e fugazes -, o narrador parece percorrer uma trajetória iniciática singular, cujo efeito principal poderia ser sintetizado em um excerto de uma das primeiras cartas de Caio F. redigidas após sua internação.

Passeio pelos corredores da enfermaria e vejo cenas. Figuras estarrecedoras. Saio dessa mais humano e infinitamente melhor, mais paciente - me sinto privilegiado por poder vivenciar minha própria morte com lucidez e fé. (ABREU, 2002, p.312)

Mais não fosse, seríamos levados a crer que o aprendizado íntimo do escritor assemelhar-se-ia a uma jornada redentora que, apesar de não desejada, teria resultado dignificadora da própria existência.

Ora, o diapasão resignado da narrativa pode, a nosso ver, ser compreendido igualmente como efeito da implacável captura do sujeito pelas práticas médico-hospitalares, as quais perpetrarão a subscrição pessoal daquele que é seu objeto de intervenção à condição subjetiva de doente, incluído aí todo o aparato normativo que tal subscrição pressupõe e acarreta. Ao deparar com a crueza da vida disposta nos corpos de seus semelhantes encerrados nas enfermarias, só restaria a Caio F. a adesão íntima a determinado modo de vida marcado pelo reconhecimento da própria vulnerabilidade de existir, esta paradoxalmente recodificada em privilégio de restar vivo, ainda. Desponta aí o sobrevivente; desaparece o vivente. Caio F. torna-se um doente.

É exatamente esse tipo de naturalização da experiência ético-política do adoecimento que nos interessa, aqui, colocar sob suspeita, por meio de algumas questões-chave: qual o tipo de associação - não necessária, tanto menos suficiente - entre a 
prática da internação e a conversão subjetiva daqueles que a ela são submetidos? Em outros termos, por que a vivência de um tratamento médico-hospitalar ter-se-ia convertido em motivo e ocasião de um progresso humanizador, por meio de um aprimoramento corretivo de si? Qual, enfim, o nexo subjetivador das operações de autogoverno aí em curso, as quais redundariam na assunção de valores supostamente mais elevados como paciência, humildade, bonificação espiritual e, por fim, fé lúcida?

Para que seja possível traçar um plano de pensamento capaz de se esgueirar dos rebatimentos metafísicos tantos que se perfilam quando o assunto é o adoecimento e, em última instância, a morte, recorramos a Michel Foucault.

\section{Ordenação}

Em uma conferência proferida no Rio de Janeiro em 1974, o pensador francês esquadrinha historicamente o nascimento do hospital como instrumento terapêutico na Modernidade. É preciso lembrar que os hospitais, tal como os conhecemos hoje, têm uma história recente e, anteriormente a seu advento no século XVIII, deveras desassociada da prática médica.

Até o século XVIII, o personagem ideal do hospital não era o doente, aquele que se devia tratar, mas o pobre já moribundo. Trata-se aqui de uma pessoa que necessita de uma assistência material e espiritual, que precisava receber os últimos recursos e os últimos sacramentos. Essa era a função essencial do hospital. (FOUCAULT, 2011, p.447)

O intento principal do cuidado hospitalar, até então, não era a cura do doente, mas sua salvação espiritual a cargo de religiosos ou leigos. Não a medicina, mas a caridade, portanto, era a estratégia social mobilizada para segregar os indivíduos pobres e doentes, afetados por um duplo estigma: insalubridade e perigo.

A associação entre medicina e hospital passa a se dar apenas a partir da conquista deste por aquela no alvorecer da Modernidade, por meio da anulação da desordem tanto sanitária (as quarentenas a fim de evitar as epidemias, por exemplo) quanto econômico-social (o combate ao tráfico de mercadorias etc.) que ali reinava. Foucault relembra que foi nos hospitais marítimos e militares, bem antes do que em sua modalidade civil, que a reorganização dessa instituição ocorrera.

Alega o pensador francês que foi por meio do espraiamento da tecnologia disciplinar que um novo modo de gestão dos homens, fossem eles doentes ou não, despontou no Ocidente. Uma nova tecnologia destinada a "governar o homem, controlar seus múltiplos aspectos, utilizá-los ao máximo e melhorar o produto útil de 
seu trabalho, de suas atividades, graças a um sistema de poder que permite controlá-Io" (FOUCAULT, 2011, p.451).

No caso do hospital, a disciplinarização de suas práticas requereu um correspondente reordenamento do saber e da ação médicos, não mais circunscritos às características específicas das doenças, mas voltados às condições ambientais que as engendravam. Foi preciso também ajustar a localização dos hospitais ao esquadrinhamento sanitário das cidades, bem como calcular a distribuição interna de seus espaços, de modo que também sua arquitetura passasse a ser um fator e instrumento de cura. Haveria igualmente a transformação do sistema de poder interno dos hospitais, por meio da hierarquia absoluta da figura do médico sobre os outros atores institucionais. Soma-se, por fim, o advento de uma sistemática de registro permanente, exaustivo e individualizante dos pacientes, propiciando a irrupção de um campo documental responsável pela formação de um saber duplo, sobre o indivíduo e sobre a população; um saber biopolítico, mais precisamente.

Com efeito, vê-se despontar aí uma rede concatenada de práticas disciplinares institucionalizadas operando em íntima consonância e com vistas à vigilância perpétua dos indivíduos doravante distribuídos e esquadrinhados individualmente. Assim, hospital, escola, fábrica, exército e, por fim, prisão passariam a operar de acordo com uma economia normativa comum, responsável, por sua vez, pela produção minuciosa de saberes estruturados em torno de procedimentos de registro, de documentação etc. Daí a mútua implicação entre a formação dos saberes humanísticos e as tecnologias de poder, redundando em processos de subjetivação ordenados intrinsecamente em torno da norma.

Desta feita, não se trataria apenas do controle saturante e docilizador dos corpos, mas da edificação de uma alma sempre em dívida e a reboque de seu tempo, fosse ela dos escolares, dos trabalhadores, dos condenados ou dos doentes. É o que faz Foucault afirmar, em outra ocasião, que a alma moderna é uma realidade irredutivelmente histórica, a qual,

\footnotetext{
Diferentemente da alma representada pela teologia cristã, não nasce faltosa e merecedora de castigo, mas nasce antes de procedimentos de punição, de vigilância, de castigo e de coação. Esta alma real e incorpórea não é absolutamente substância; é o elemento onde se articulam os efeitos de um certo tipo de poder e a referência de um saber, a engrenagem pela qual as relações de poder dão lugar a um saber possível, e o saber reconduz e reforça os efeitos de poder. (FOUCAULT, 1996, p.31)
}

Uma alma fabril, artefato e, ao mesmo tempo, engrenagem basal da maquinaria do (auto) governo. Uma alma prisioneira e, ao mesmo tempo, transcendente; ponto 
preciso de confluência entre a vida e a história. Uma alma-identidade, a se arrastar no infinito do presente.

Ora, se for plausível assumirmos uma correspondência entre o processo de internação hospitalar e a conversão identitária dos sujeitos a ela submetidos - como em Caio F. -, será possível também deduzir que outros horizontes ético-políticos seriam igualmente factíveis, face a esse tipo de experiência. Daí a hipótese central, aqui, de que a tarefa inexorável das práticas artísticas e, em particular, as teatrais é apenas uma: a de franquear abrigo e vazão para a potência da vida, esta que, mesmo no duelo-limite com a morte, pode constituir-se como fonte de insuspeitas resistência e criação.

Eis o que vislumbramos quando em confronto com a experiência proporcionada por Pulsão.

\section{Rebentação}

O trabalho levado a cabo pelo Coletivo Desvio devota-se, como se sabe, à reinvenção cênica da sucessão de eventos que se precipitaram a partir de uma internação hospitalar ocasionada por uma doença agressiva e sem diagnóstico, protagonizada pelo idealizador e diretor do espetáculo, Marcos Bulhões. A bem da verdade, a obra definir-se-ia, segundo seu criador, como legatária imediata de tal experiência - uma prova única de mais-vida, por assim dizer. Contudo, é precisamente o transbordamento de tal experiência pessoal que, a nosso ver, constitui a matéria-prima de Pulsão.

De imediato, há de se assinalar a ocupação performativa do espaço teatral pelo Coletivo, afrontando, assim, a narratividade tão faustosa quanto doutrinária que há séculos constitui a tônica dominante do que se passa entre palco e plateia. Em Pulsão, esta não há, já que todos sofrem os mesmos efeitos de um confinamento compulsório que, ao final, se transmutará em algo extraordinário e inusitado, já que muito raramente testemunhado entre as produções teatrais. De outro ponto de vista, trata-se da invenção de um espaço heterotópico - fugaz, viril e desmesurado - em que teatro e vida tornam-se indistinguíveis, por meio da forja de um intervalo de suspensão da própria experiência pessoal, seja dos atores, seja do público.

Isso significa que o trabalho dramatúrgico ali disposto propõe-se não a narrar o longo périplo de uma vida extorquida pela dor, mas a transtorná-lo cenicamente ponto a ponto, proporcionando, assim, uma vigorosa imersão performativa, por um lado, na ambiência típica de uma prática responsável pela desqualificação/requalificação de 
um corpo exangue e, por outro, na exploração do universo possível de escolhas que restam àqueles por ela interceptados.

Em Pulsão, nada parece se avizinhar a um ensejo de transcendência, de aquiescência ou de apaziguamento, mas tão somente à edificação de paragens nômades obstinadas o bastante para abrigar e, quem sabe, fazer proliferar o vigor irredutível de um corpo aberto, não obstante o sem-número de riscos que isso impõe.

Não é um corpo utópico o que lá se perfaz, tal como aquele descrito por Foucault (2013, p.8): "[...] um corpo sem corpo, um corpo que seria belo, límpido, transparente, luminoso, veloz, colossal na sua potência, infinito na sua duração, solto, invisível, protegido, sempre transfigurado," tanto menos aquele desdobrado pelo grande mito da alma, quimericamente capaz de ultrapassar a ruína e a extinção de sua própria matéria, convertendo-se em algo "luminoso, purificado, virtuoso, ágil, móvel, tépido, viçoso; [...] liso, castrado, arredondado como uma bolha de sabão.' (FOUCAULT, 2013, p.9)

Não. Em Pulsão, não são os esotéricos ritos de passagem da morte ou do sobrenatural que ali se afiguram, mas a potência em ato de um corpo qualquer e sua capacidade variável de resistir à banalidade de seu próprio fim. Ainda com Foucault (2013, p. 10): “Não, verdadeiramente não há necessidade da mágica nem do feérico, não há necessidade de uma alma nem de uma morte para que eu seja ao mesmo tempo opaco e transparente, visível e invisível, vida e coisa”.

Um corpo que lateja, que treme e que estala sem cessar ao deambular na exiguidade sovina do tempo/espaço sempre em distrato conosco. Um corpo cujo fluxo vital ganha espessura exatamente lá onde a captura médica antes decretava seu esgotamento paulatino e irremediável. Um corpo informe, que irrompe exatamente lá onde se supunha quase mais nada haver. Um corpo desalmado, que nada espera e que, portanto, sequer suspeita o que pode.

Se, num primeiro plano, o que está em jogo em Pulsão é a dramaturgia funesta de um corpo em vias de desaparecimento, logo em seguida rebenta a beleza trágica de uma existência que se insurge, que se contorce, que uiva, que se lança para além do improvável.

Para nós, os vivos, tudo ainda é cedo. Ou pouco.

\section{Referências}

ABREU, Caio Fernando. Pequenas epifanias. Porto Alegre: Sulina, 1996.

Cartas. Rio de Janeiro: Aeroplano, 2002.

FOUCAULT, Michel. Vigiar e punir: nascimento da prisão. Petrópolis: Vozes, 1996. 
A incorporação do hospital na tecnologia moderna. In: Arte, Epistemologia, Filosofia e História da Medicina. Rio de Janeiro: Forense Universitária, 2011. p.444-458. (Ditos e escritos VII)

O corpo utópico; As heterotopias. São Paulo: n-1 Edições, 2013.

Recebido em 17/03/2014

Aprovado em 30/04/2014

Publicado em 25/06/2014 